\title{
Identification of chemical constituents of Zanthoxylum heitzii stem bark and their insecticidal activity against the malaria mosquito Anopheles gambiae
}

\author{
Nastaran Moussavi ${ }^{1}$, Karl Egil Malterud', Bertin Mikolo², Dag Dawes ${ }^{1}$, Fabrice Chandre ${ }^{3}$, Vincent Corbel ${ }^{3}$, \\ Daniel Massamba², Hans J. Overgaard ${ }^{3,4,5}$ and Helle Wangensteen ${ }^{1 *}$
}

\begin{abstract}
Background: Zanthoxylum heitzii bark extracts have insecticidal properties and have been reported to be used against malaria in Western Africa. Previously, it has been shown that a hexane extract of the bark is toxic to adult females of the mosquito Anopheles gambiae, a malaria vector. As part of our project on the control of malaria vectors using plant extracts, the phytochemistry of $Z$. heitzii bark hexane extract has been investigated with the aim to identify the major components with adulticidal and larvicidal effects on An. gambiae.

Methods: Z. heitzii stem bark was extracted with hexane, and the extract was fractionated to isolate major components from the bark, identified by NMR spectroscopy. Isolated compounds were tested for toxicity towards adult female An. gambiae mosquitoes and for larvicidal effects towards An. gambiae.

Results: The alkaloid dihydronitidine, the sesquiterpenoid caryophyllene oxide, the amide pellitorine and the lignan sesamin were identified as the major constituents in Z. heitzii bark. Pellitorine was toxic to both adult insects $\left(\mathrm{LD}_{50} 50 \mathrm{ng} / \mathrm{mg}\right.$ insect) and larvae $\left(\mathrm{LD}_{50} 13 \mu \mathrm{g} / \mathrm{ml}\right)$. None of the other compounds were toxic to adults, but caryophyllene oxide and sesamin exhibited moderate larvicidal effects $\left(\mathrm{LD}_{50}>150 \mu \mathrm{g} / \mathrm{ml}\right)$. A mixture of the four compounds in the same ratio as in the hexane extract showed higher toxicity ( $\mathrm{LD}_{50} 34 \mathrm{ng} / \mathrm{mg}$ insect) towards adult insects than the pure compounds.
\end{abstract}

Conclusion: The toxicity of $Z$. heitzii bark hexane extract to An. gambiae is mostly due to pellitorine, although interactions between pellitorine and other, inactive constituents may enhance the activity of the extract.

Keywords: Zanthoxylum heitzii, Anopheles gambiae, Pellitorine, Malaria, Insecticide

\section{Background}

Malaria infection is estimated to kill more than 600000 people every year, the majority of which are children below five years old [1]. Insecticides to kill or repellents to deter mosquitoes from biting are the mainstay of malaria vector control. However, mosquito resistance to commonly used insecticides (e.g. pyrethroids) is a major challenge [2]. There is therefore an urgent need for new and alternative insecticides. The tree Zanthoxylum

\footnotetext{
* Correspondence: helle.wangensteen@farmasi.uio.no

${ }^{1}$ School of Pharmacy, Department of Pharmaceutical Chemistry, Section

Pharmacognosy, University of Oslo, P.O. Box 1068 Blindern, 0316 Oslo, Norway Full list of author information is available at the end of the article
}

heitzii (Aubrév. \& Pellegr.) P.G. Waterman, syn. Fagara heitzii Aubrév. \& Pellegr., Rutaceae, is a West African species found in forests from Congo to Cameroon [3]. Some of its local names are olon [3] and bouboulou [4]. This tree is used for timber, but has also a considerable ethnopharmacological use. The diseases for which it is used include jaundice [5], toothache [6], gonorrhoea [7], rheumatic ailments and stiff joints, impotence [3, 7] and malaria [3]. It has also been used as a fish poison [3]. Chemically and pharmacologically, this plant has only been subjected to a limited amount of research. This species has been shown to contain alkaloids, phenols, saponins, mucilage [8] and terpenoids [9]. More

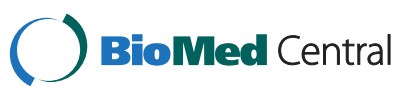

(c) 2015 Moussavi et al. Open Access This article is distributed under the terms of the Creative Commons Attribution 4.0 International License (http://creativecommons.org/licenses/by/4.0/), which permits unrestricted use, distribution, and reproduction in any medium, provided you give appropriate credit to the original author(s) and the source, provide a link to the Creative Commons license, and indicate if changes were made. The Creative Commons Public Domain Dedication waiver (http://creativecommons.org/publicdomain/zero/1.0/) applies to the data made available in this article, unless otherwise stated. 
specifically, the alkaloids arnottianamide, fagaramide, iso- $\gamma$-fagarine, iso- $\gamma$-skimmianine, skimmianine and nitidine have been reported from the bark [10-12], flindersine [13] from the wood, and 6-methylnitidine [12] and iso- $\gamma$-skimmianine [10] from the roots. Two novel amides, heitziamide A and B, and two novel aromatic fatty acid esters, heitziethanoid A and B, were reported from the bark, as well as methyl esters of long-chain fatty acids [10]. The bark contains a variety of lignans $[10,11]$, and sterols and triterpenes have also been isolated from the bark or roots $[10,12]$. Z. heitzii extracts have been shown to be active against Gram-positive bacteria [14], filarial worms [9], and two different cancer cell lines [14]. Antioxidant effects and activity against sickle cell anemia in vitro are reported [8], as well as immunorestorative properties of an aqueous bark extract in clinical studies [15]. The bark extract was also toxic towards agricultural weevil pests and the cockroach Periplaneta americana L. [4]. The effect of $Z$. heitzii extracts on adult females of the mosquito Anopheles gambiae Giles, a major vector of malaria, has recently been investigated by us [16]. After extracting diverse plant parts from $Z$. heitzii with solvents of different polarities, the hexane stem bark extract was found to be the most active against An. gambiae. The aim of this study was to identify the major components from the hexane stem bark extract with adulticidal and larvicidal effects on An. gambiae.

\section{Methods}

\section{Plant material}

Stem bark of Zanthoxylum heitzii was taken from a tree in Douakani, Republic of Congo, in November 2011.
The tree was identified by one of the authors (B. Mikolo). A voucher sample of the bark is kept in the Section of Pharmacognosy, School of Pharmacy, University of Oslo (registry number ZH-B-111202).

\section{Preparation of extract}

The bark was air-dried and milled in a knife mill $(4 \mathrm{~mm}$ sieve). Of the powdered bark, aliquots of ca $300 \mathrm{~g}$ were extracted with 3 liter portions of hexane in a Soxhlet extractor for $10 \mathrm{~h}$. After cooling to room temperature, the solvent was removed on a rotary evaporator, and the dry extracts weighed. Average yield of extract was ca $1.9 \%$ $(\mathrm{w} / \mathrm{w})$. A scheme of the extraction and fractionation processes is shown in Fig. 1.

\section{General experimental procedures}

Column chromatographic separation was done on prepacked Versapak normal phase Si gel columns (VersaFlash system; Supelco, Bellefonte, PA, USA) and preparative centrifugally accelerated thin-layer chromatography (CA-TLC) on a Chromatotron model $7924 \mathrm{~T}$ (Harrison Research, Palo Alto, CA, USA), using 1 or $2 \mathrm{~mm}$ layers of Si gel $60 \mathrm{PF}_{254}$ containing gypsum (Merck, Darmstadt, Germany). Analytical TLC was carried out on $0.2 \mathrm{~mm}$ Si gel $60 \mathrm{~F}_{254}$ plates (Merck). Spots were visualized by irradiation with short-wave $(254 \mathrm{~nm})$ and long-wave $(366 \mathrm{~nm}) \mathrm{UV}$ rays (UVGL-58 instrument, Ultra-Violet Products, Upland, CA, USA) and by spraying with a $1 \%$ solution of $\mathrm{Ce}\left(\mathrm{SO}_{4}\right)_{2}$ in $10 \%$ aqueous $\mathrm{H}_{2} \mathrm{SO}_{4}$ followed by heating to $105{ }^{\circ} \mathrm{C}$ for $5 \mathrm{~min}$. One- and two-dimensional NMR spectra were recorded in $\mathrm{CDCl}_{3}$ solution on a Bruker DPX300 instrument

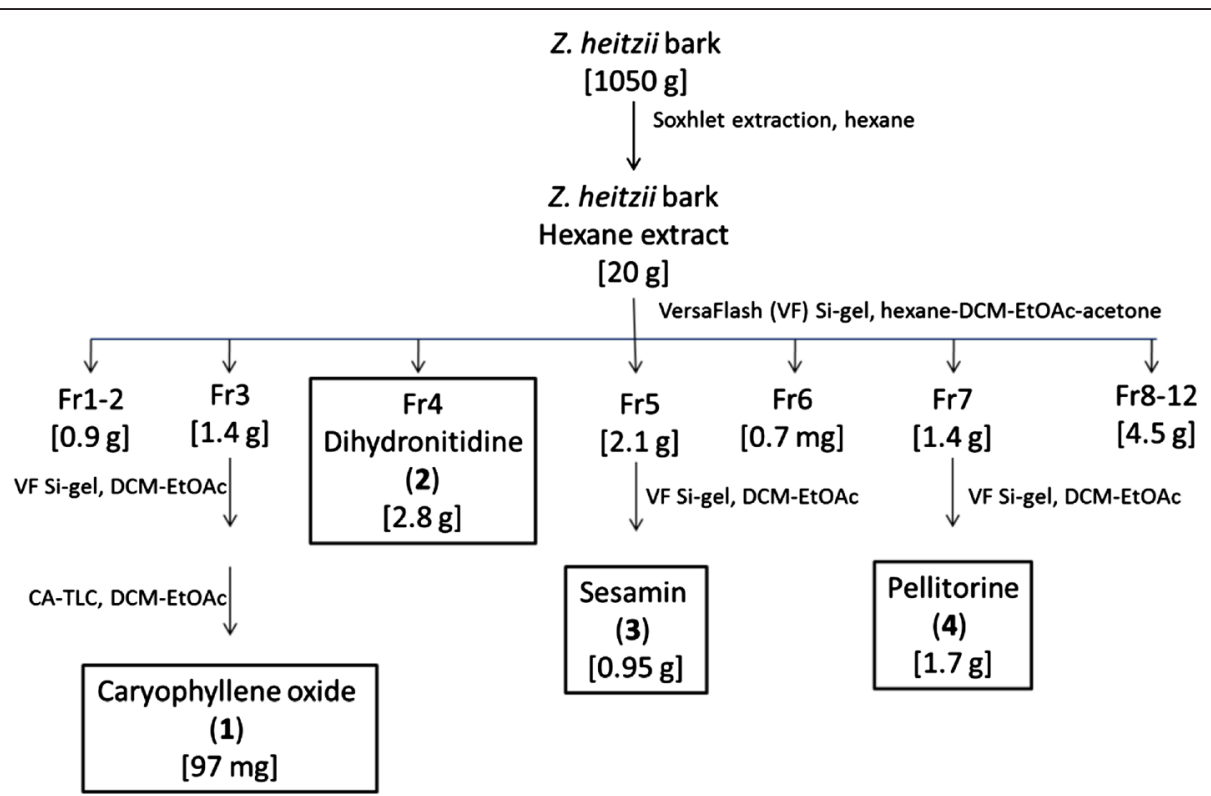

Fig. 1 Flow scheme for extraction and isolation of compounds from Zanthoxylum heitzii bark. Abbreviations: VF: VersaFlash chromatography; CA-TLC: centrifugally accelerated thin layer chromatography; DCM: dichloromethane; EtOAc: ethyl acetate 
or a Bruker AVII400 instrument (Bruker, Rheinstetten, Germany) at $300 \mathrm{MHz}$ for ${ }^{1} \mathrm{H} / 75 \mathrm{MHz}$ for ${ }^{13} \mathrm{C}$ and $400 \mathrm{MHz}$ for ${ }^{1} \mathrm{H} / 100 \mathrm{MHz}$ for ${ }^{13} \mathrm{C}$, respectively. HPLC analysis was performed on a LaChrom Elite HPLC system (Hitachi, Tokyo, Japan) equipped with an L-2455 diode array detector. A Chromolith Performance RP18e $100 \mathrm{x}$ $4.6 \mathrm{~mm}$ column (Merck) was used for separation. Elution was performed using a gradient of mobile phase A (water) and mobile phase $\mathrm{B}$ (acetonitrile) with the following time schedule: $20 \%$ B, 0-1 min; 20-95 \% B, 1-15 min; $95 \%$ B, 15-16 min. The concentration of injected samples was $0.5 \mathrm{mg} / \mathrm{mL}$, injection volume was $10 \mu \mathrm{L}$ and flow rate was $3.0 \mathrm{~mL} / \mathrm{min}$. The absorbance was recorded at $237 \mathrm{~nm}$, and separation took place at $25{ }^{\circ} \mathrm{C}$. All chemicals and solvents were of the highest quality available.

\section{Fractionation of the crude extract}

$\mathrm{Ca} 20 \mathrm{~g}$ of the dried hexane extract of $Z$. heitzii stem bark was dissolved in $100 \mathrm{~mL}$ dichloromethane (DCM), filtered, and applied to a Versapak Si gel column (110 x $300 \mathrm{~mm}$ ) conditioned with hexane-DCM, 1:1. The column was eluted with a hexane-DCM-ethyl acetate (EtOAc) - acetone gradient, and 37 fractions of 0.15 $0.5 \mathrm{~L}$ were collected and combined into major fractions Fr1-Fr12 as indicated by analytical TLC (mobile phase DCM or DCM-EtOAc, 1:1). All combined fractions were subjected to ${ }^{1} \mathrm{H}$ NMR spectroscopy.

\section{Purification and isolation of compounds}

Fraction Fr3 (ca 1.4 g) from the crude extract was rechromatographed on a Versapak Si gel column $(40 \times 150 \mathrm{~mm})$ with a DCM-EtOAc gradient, yielding fractions Fr3V1Fr3V13. After combination of fractions as above, Fr3V6 $(0.35 \mathrm{~g})$ was purified by CA-TLC (2 mm layer, DCMEtOAc gradient), yielding fractions Fr3V6C1-Fr3V6C5. Fr3V6C4 (97 mg) was identified as compound 1 by one$\left({ }^{1} \mathrm{H},{ }^{13} \mathrm{C} / \mathrm{APT}\right)$ and two-dimensional (COSY, HSQC)
NMR spectroscopy. Fraction Fr4 (2.8 g) gave crystals on standing in DCM solution at room temperature. The crystals (ca $1.6 \mathrm{~g}$ ) were filtered off and washed with small amounts of cold DCM, and their purity was tested by TLC. ${ }^{1} \mathrm{H}$ and ${ }^{13} \mathrm{C} / \mathrm{APT}$ NMR spectra were recorded to identify compound 2. Fraction Fr5 (ca 2.1 g), was dissolved in DCM and applied to a Versapak Si gel column $(40 \times 150 \mathrm{~mm})$. Elution with a DCM-EtOAc gradient gave nine major fractions, Fr5V1-Fr5V9, which were characterized by ${ }^{1} \mathrm{H}$ NMR. Fr5V2 (1.2 g) was further purified by repeated Versapak chromatography to obtain compound $3(0.50 \mathrm{~g})$. The same compound was also the main component of Fr5V3 (0.45 g). ${ }^{1} \mathrm{H}$ and ${ }^{13} \mathrm{C} / \mathrm{APT}$ NMR spectroscopy was employed to characterize compound 3. Fraction Fr7 (3.3 g) was rechromatographed over Si gel as above. Fr7V6 $(1.7 \mathrm{~g})$ was identified by ${ }^{1} \mathrm{H}$ and ${ }^{13} \mathrm{C} / \mathrm{APT}$ NMR spectroscopy as compound 4. ${ }^{1} \mathrm{H}$ NMR spectral data for the pure substances are shown in Table 1 . Spectra of the crude extract have been published previously ([16], suppl.).

\section{Adult female mosquitoes bioassays}

A non-resistant strain of An. gambiae s.s. from Kisumu, Kenya (KIS) was used. Mosquitoes were reared at $25 \pm$ $5{ }^{\circ} \mathrm{C}$ and $80 \pm 10 \%$ humidity in the laboratory of IRD, Montpellier. Assay for topical toxicity according to standard WHO protocol [17] was done as previously described [16]. Two replicates of 25 non-blood fed 2-5 day-old female mosquitoes (average weight $1.1 \mathrm{mg}$ ), were used in each test. Solutions of test substances in different concentrations in acetone $(0.1 \mu \mathrm{L})$ were applied to the pronotum of each female mosquito, and the number of dead mosquitoes after $24 \mathrm{~h}$ was recorded. Acetone alone was used as negative control and acetone solutions of permethrin as positive control.

Table $1^{1} \mathrm{H}$ NMR data for caryophyllene oxide (1), dihydronitidine (2), sesamin (3) and pellitorine (4) $\delta$ values are in ppm, J values in $\mathrm{Hz}$. $\mathrm{CDCl}_{3}$ was used as solvent

\begin{tabular}{|c|c|c|c|}
\hline 1 & 2 & 3 & 4 \\
\hline $4.97(1 \mathrm{H}, \mathrm{d}, J 1.3)$ & $7.68(1 \mathrm{H}, \mathrm{d}, J$ 8.6) & $6.78-6.85(6 \mathrm{H}, \mathrm{m})$ & $7.18(1 \mathrm{H}, \mathrm{dd}, \mathrm{J} 10.0,15.0)$ \\
\hline $4.86(1 \mathrm{H}, \mathrm{d}, J 1.3)$ & $7.66(1 \mathrm{H}, \mathrm{s})$ & $5.95(4 \mathrm{H}, \mathrm{s})$ & $6.10(1 \mathrm{H}, \mathrm{m})$ \\
\hline $2.87(1 \mathrm{H}, \mathrm{dd}, J 10.7,4.1)$ & $7.48(1 \mathrm{H}, \mathrm{d}, J 8.6)$ & $4.72(2 \mathrm{H}, \mathrm{d}, J 4.4)$ & $6.09(1 \mathrm{H}, \mathrm{m})$ \\
\hline $2.61(1 \mathrm{H}, \mathrm{m})$ & $7.31(1 \mathrm{H}, \mathrm{s})$ & $4.24(2 \mathrm{H}, \mathrm{m})$ & $5.84(1 \mathrm{H}, \mathrm{d}, J 15.1)$ \\
\hline $0.85-2.40$ (several m) & $7.11(1 \mathrm{H}, \mathrm{s})$ & $3.88(2 \mathrm{H}, \mathrm{dd}, J 3.6,9.3)$ & $3.15(2 \mathrm{H}, \mathrm{t}, J 6.4)$ \\
\hline $1.20(3 \mathrm{H}, \mathrm{s})$ & $6.79(1 \mathrm{H}, \mathrm{s})$ & $3.05(2 \mathrm{H}, \mathrm{m})$ & $2.14(2 \mathrm{H}, \mathrm{q}, J 6.8)$ \\
\hline $1.01(3 \mathrm{H}, \mathrm{s})$ & $6.04(2 \mathrm{H}, \mathrm{s})$ & & $1.79(1 \mathrm{H}, \mathrm{m})$ \\
\hline \multirow[t]{4}{*}{$0.99(3 \mathrm{H}, \mathrm{s})$} & $4.13(2 \mathrm{H}, \mathrm{s})$ & & $1.26-1.44(6 \mathrm{H}, \mathrm{m})$ \\
\hline & $3.99(3 \mathrm{H}, \mathrm{s})$ & & $0.91(6 \mathrm{H}, \mathrm{d}, J 6.7)$ \\
\hline & $3.95(3 \mathrm{H}, \mathrm{s})$ & & $0.89(3 \mathrm{H}, \mathrm{t}, J 7.0)$ \\
\hline & $2.60(3 \mathrm{H}, \mathrm{s})$ & & \\
\hline
\end{tabular}




\section{Larvae bioassays}

Third instar larvae of the same mosquito strain as above were used in larval bioassays according to WHO guidelines [18]. Test solution in ethanol $(1 \mathrm{~mL})$ was added to four replicates of $99 \mathrm{~mL}$ osmotic water containing 20 larvae. Larvae were kept at $26-28{ }^{\circ} \mathrm{C}$ for $24 \mathrm{~h}$ and the number of surviving larvae as defined by WHO was counted. Ethanol alone $(1 \mathrm{~mL})$ in water was used as negative control. No positive control was carried out.

\section{Statistics}

Non-linear regression analysis was employed to analyse $\mathrm{LD}_{50}$ values and confidence intervals (GraphPad Prism 6.05 software).

\section{Results}

\section{Chemistry}

The hexane extract from $Z$. heitzii bark was separated by normal phase chromatography, and after analysis by NMR and TLC twelve fractions were obtained. Based on fraction weights and NMR spectra, Fr3-5 and Fr7 were chosen for further work to identify the major compounds in the extract. This resulted in four major compounds, shown in Fig. 2.

Fraction Fr3V6C4 gave NMR spectra which were consistent with a sesquiterpene structure containing an oxirane ring and a terminal methylene group. From comparison with literature data $[19,20]$, the substance was identified as caryophyllene oxide (1). The crystals from Fr4 gave NMR spectra indicative of an aromatic compound containing one methylenedioxy group, two aromatic methoxyl groups and one $\mathrm{N}$-methyl group. The compound was identified from literature data as the alkaloid dihydronitidine (2) [21]. Fractions Fr5V2 and Fr5V3 yielded an aromatic substance with two methylenedioxy groups, as evidenced by NMR. From comparison with literature data [22], the substance was identified as the lignan sesamin (3). Fraction Fr7V6 gave a compound containing an isobutyl group, a carbonyl group and two $\mathrm{C}=\mathrm{C}$ double bonds (NMR). This compound was identified as the amide pellitorine (4) from literature data [22]. Data for our spectra are shown in Table 1. Based on weights and estimated purity (from ${ }^{1} \mathrm{H} \mathrm{NMR}$ ), a weight ratio of caryophyllene oxide : dihydronitidine : sesamin : pellitorine in the crude extract of ca $4: 31: 26: 39$ was calculated. This is not an analytical result, but only an approximation.

\section{Insecticidal activity}

Pellitorine showed a toxic effect towards mosquitoes. From nine separate experiments, an $\mathrm{LD}_{50}$ value of $50 \mathrm{ng} / \mathrm{mg}$ mosquito was found (Table 2), with a nearly linear correlation between log concentration and mortality (Fig. 3). The positive control, permethrin, had an $\mathrm{LD}_{50}$ value of $1.9 \mathrm{ng} / \mathrm{mg}$ mosquito. For the negative control, acetone, mortality values of 3-5\% were found. The other $Z$. heitzii substances tested were regarded as non-toxic: caryophyllene oxide $(6 \pm 3 \%$ mortality at $100 \mathrm{ng} / \mathrm{mg}$ mosquito, $6 \%$ at $1000 \mathrm{ng} / \mathrm{mg}$ mosquito), dihydronitidine $(6 \pm 3 \%$ mortality at $100 \mathrm{ng} / \mathrm{mg}$ mosquito, $23 \%$ mortality at $1000 \mathrm{ng} / \mathrm{mg}$ mosquito) and sesamin $(9 \pm 2 \%$ mortality at $100 \mathrm{ng} / \mathrm{mg}$ mosquito, $15 \%$ mortality at $1000 \mathrm{ng} / \mathrm{mg}$ mosquito). Due to scarcity of pure substances, the values are averages of two experiments at $1000 \mathrm{ng} /$ mosquito. Since interactions between the different compounds might be present, a mixture of caryophyllene oxide, dihydronitidine, sesamin, and pellitorine was tested. This mixture had approximately

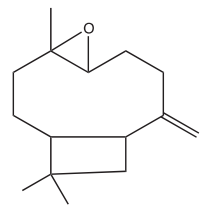<smiles>COc1cc2c(cc1OC)-c1ccc3cc4c(cc3c1N(C)C2)OCO4</smiles>

Caryophyllene oxide (1)

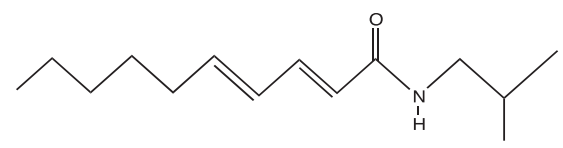

Pellitorine (4)

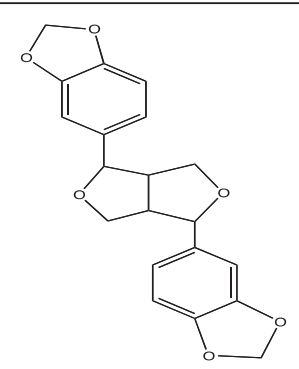

Sesamin (3)

Fig. 2 Structures of isolated compounds from Zanthoxylum heitzii stem bark 
Table 2 Insecticidal and larvicidal activity against Anopheles gambiae of isolated compounds from Z. heitzii stem bark

\begin{tabular}{|c|c|c|c|c|c|c|}
\hline \multirow[t]{2}{*}{ Test compound } & \multicolumn{3}{|l|}{ Insecticidal activity } & \multicolumn{3}{|c|}{$\underline{\text { Larvicidal activity }}$} \\
\hline & $\mathrm{LD}_{50}$ (ng/mg adult female) & $95 \% \mathrm{Cl}$ & Slope & $\mathrm{LD}_{50}(\mu \mathrm{g} / \mathrm{ml})$ & $95 \% \mathrm{Cl}$ & Slope \\
\hline Caryophyllene oxide (1) & $>1000$ & & & $185^{\mathrm{e}}$ & 175-196 & 7.4 \\
\hline Dihydronitidine (2) & $>1000$ & & & $n t^{a}$ & & \\
\hline Sesamin (3) & $>1000$ & & & $>150$ & & \\
\hline Pellitorine (4) & $50^{c}$ & $43-57$ & 1.1 & $13^{f}$ & $12-14$ & 4.6 \\
\hline Mixture of $\mathbf{1}-\mathbf{4}^{\mathrm{b}}$ & $34^{\mathrm{d}}$ & $28-38$ & 2.2 & $\mathrm{nt}^{\mathrm{a}}$ & & \\
\hline Permethrin (positive control) & $1.9^{\mathrm{d}}$ & $1.7-2.2$ & 1.9 & $\mathrm{nt}^{\mathrm{a}}$ & & \\
\hline
\end{tabular}

${ }^{a}$ nt: not tested; ${ }^{b}$ The ratio of compounds 1-4 was 4:31:26:39; ${ }^{c} 9$ experiments, each with $2 \times 25$ mosquitoes; ${ }^{d} 4$ experiments, each with $2 \times 25$ mosquitoes; ${ }^{\text {e }} 5$ experiments, 4 with $4 \times 20$ larvae, one with $2 \times 20$ larvae; ${ }^{4} 4$ experiments, 2 with $4 \times 20$ larvae, 2 with $2 \times 20$ larvae

the same weight ratio between substances $\mathbf{1 - 4}$ as in the hexane extract (see above). The mixture showed toxicity towards mosquitoes with an $\mathrm{LD}_{50}$ value of $34 \mathrm{ng} / \mathrm{mg}$ mosquito. This mixture (100 ng/mg mosquito) produced a mortality of $99 \pm 2 \%$ compared to $56 \pm 22 \%$ for pellitorine alone (100 ng/mg mosquito). The concentration of pellitorine in the mixture that gives $50 \%$ toxicity is $14 \mathrm{ng} / \mathrm{mg}$ mosquito. At this concentration, an expected mortality of ca $18 \%$ is derived from the regression line in Fig. 3; about half of the mortality of the mixture. Pellitorine was the major larvicidal constituent of the extract with an $\mathrm{LD}_{50}$ value of $13 \mu \mathrm{g} / \mathrm{ml}$ and $100 \%$ mortality at $25 \mu \mathrm{g} / \mathrm{ml}$ (Fig. 4). Caryophyllene oxide and sesamin showed moderate toxicity (mortality at $150 \mu \mathrm{g} / \mathrm{ml}: 22 \pm 10 \%$ and $23 \pm 3 \%$, respectively). Dihydronitidine was insoluble in the assay system and was not tested. Ethanol (negative control, $1 \%$ concentration) was non-toxic to mosquito larvae.

\section{Discussion}

The present work showed that the hexane extract from Z. heitzii bark has a relatively simple phytochemical composition (Fig. 5), with pellitorine, dihydronitidine and sesamin as the major compounds (ratio 39:31:26 based on fraction weights and integration of ${ }^{1} \mathrm{H}$ NMR

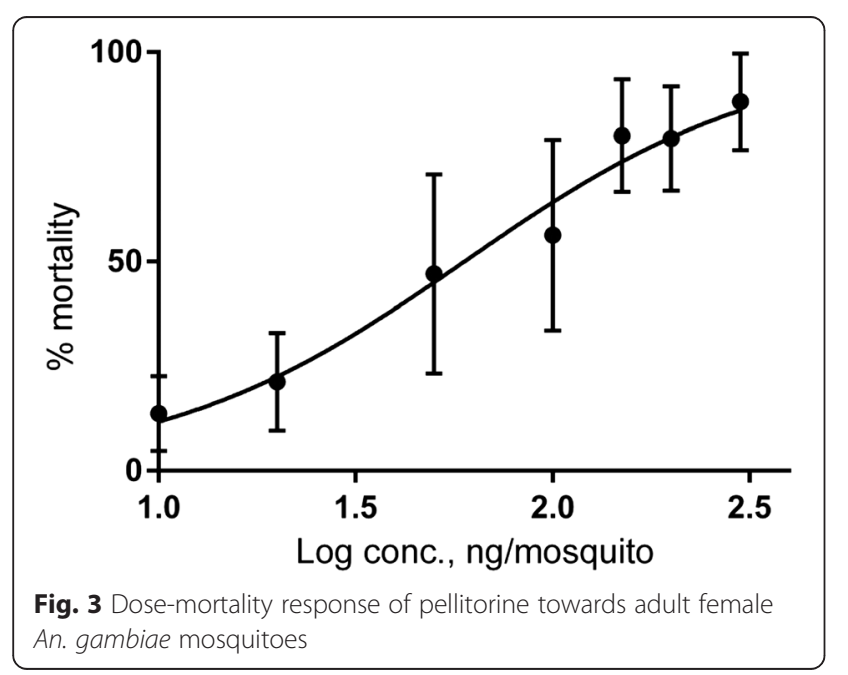

spectra of the crude extract). Caryophyllene oxide was found as a minor component. Pellitorine, dihydronitidine and caryophyllene oxide are for the first time (as far as we know) reported from $Z$. heitzii. They have, however, previously been reported from other Zanthoxylum species. Sesamin has previously been reported in $Z$. heitzii bark $[10,11]$. Caryophyllene oxide is a commonly occurring compound in nature and has previously been found in several Zanthoxylum species [23-25], although not in Z. heitzii.

Pellitorine was the active component against mosquitoes, although its activity was less than that of the positive control permethrin ( $\mathrm{LD}_{50} 50$ vs. $1.9 \mathrm{ng} / \mathrm{mg}$ mosquito). This is the first study showing activity of pellitorine towards adult Anopheles mosquitoes, although it has been reported to be toxic towards other mosquito species such as Culex pipiens pallens L. and Aedes aegypti L. [26]. Caryophyllene oxide itself appears not to have been tested previously for toxicity towards adult An. gambiae mosquitoes. In our experiments, it was inactive. While caryophyllene oxide often is a constituent of essential oils with effect on mosquitoes [27], it would seem from our results

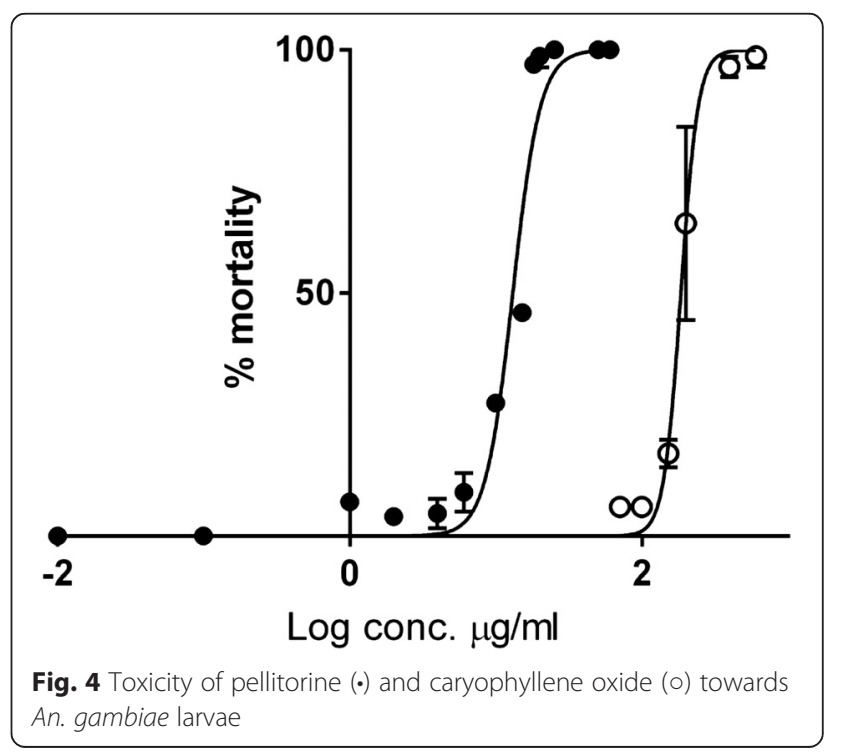




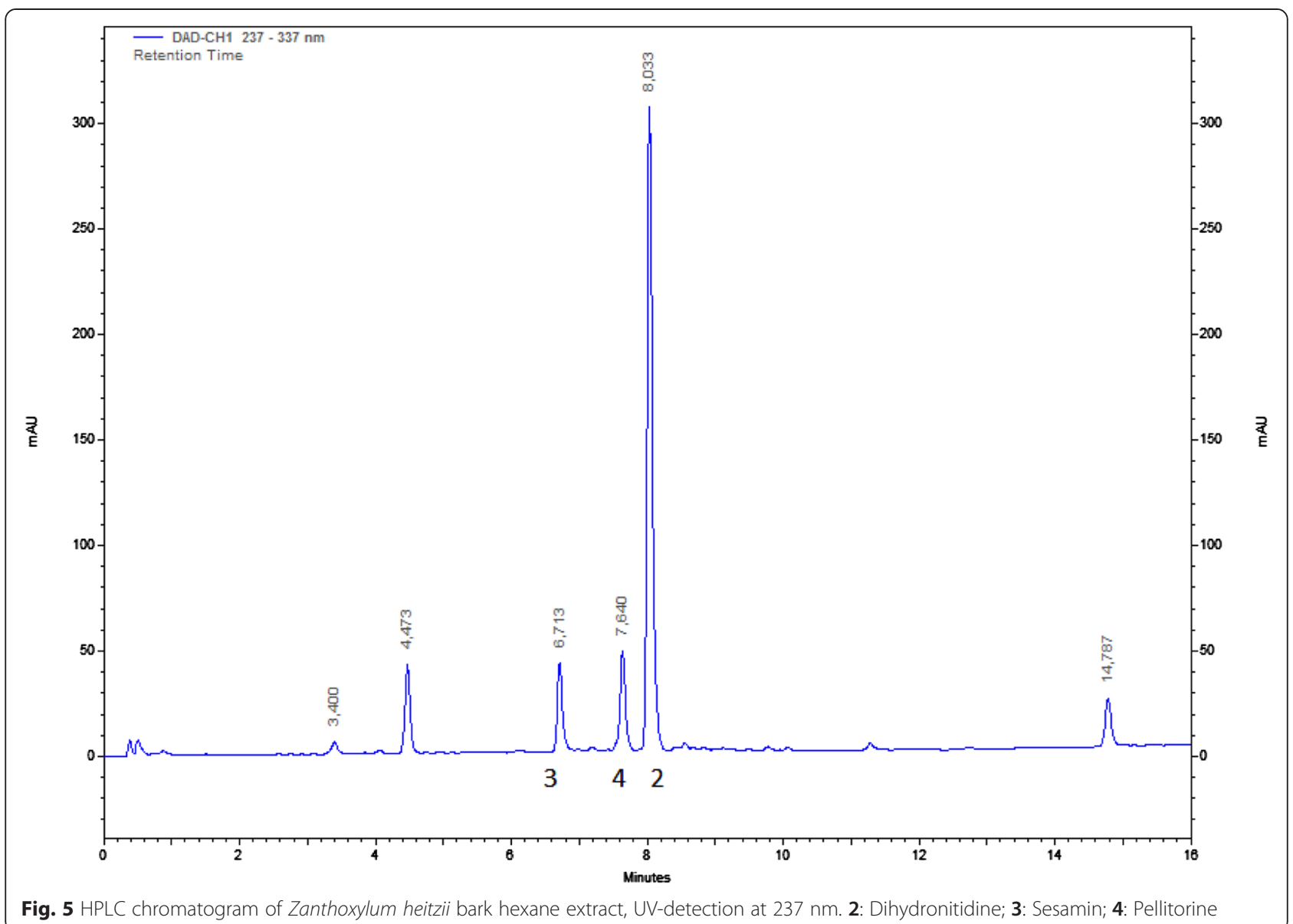

that it is not one of the active components of these oils, although synergistic effects cannot be excluded. Sesamin and dihydronitidine were both inactive against adult $A n$. gambiae females. No reports have been found on previous investigations on the toxicity of these compounds against An. gambiae adults. However, sesamin is known for synergistic effects together with pyrethroid insecticides which was reported in a study against houseflies in the early 1940s [28], and has since then also been found to exert synergistic activities in other biological systems, e.g. as antihypertensive agent together with vitamin $\mathrm{E}$ in rats [29]. The mechanisms behind the synergistic effects are not known in detail. One possibility is that sesamin (a wellknown inhibitor of CYP enzymes due partly to its methylene dioxy structure $[30,31])$ inhibits cytochrome P450-dependent monooxygenases. The CYP enzymes are present both in insects and mammals and are involved in the metabolism of exogenous compounds, as well as insecticides. Resistance to insecticides may develop due to increased monooxygenase activity which will result in lower insecticide uptake. Therefore, inhibition of CYP450s may be favourable in counteracting insecticide resistance and CYP inhibitors may also increase the uptake and work synergistically with insecticides that are detoxified by the P450s [32]. Terpenoids are also potential synergistic agents, e.g. essential oils which are rich in mono- and sesquiterpenoids have been shown to increase the activity of commercial insecticides [33], although such an effect has apparently not been reported for caryophyllene oxide. It is noteworthy that the mixture of constituents showed higher activity than pellitorine alone, with close to $100 \%$ mortality at $100 \mathrm{ng} / \mathrm{mg}$ mosquito. It would seem reasonable that this is due to interaction or synergistic effects between the active constituent pellitorine and the inactive ones, caryophyllene oxide, sesamin and dihydronitidine. This activity is considerably higher than what was found for the crude extract $\left(\mathrm{LD}_{50} 102 \pm 14 \mathrm{ng} / \mathrm{mg}\right.$ mosquito [16]), making it unlikely that other, unidentified components of the extract are important contributors to the total activity of the extract. However, it would be of interest to further study the insecticidal potential of mixtures of these compounds in different ratios to see how variation in the ratio between these components can affect insecticidal activity, and also to study the combination of pellitorine with sesamin as a potential synergistic agent. In view of the increased activity of the mixture of components compared to pellitorine alone, it might also be worthwhile to investigate the possibility of using $Z$. heitzii hexane bark 
extracts and the active compound pellitorine in combination with other insecticides.

As was the case for adult mosquitoes, pellitorine was the active constituent against mosquito larvae, with an $\mathrm{LD}_{50}$ value of $13 \mu \mathrm{g} / \mathrm{ml}$. Pellitorine has not been reported previously to be toxic towards An. gambiae larvae, although the compound is known to be toxic towards larvae of other mosquitoes such as Culex pipiens pallens and Aedes aegypti [34, 35]. Caryophyllene oxide and sesamin had only low activity on An. gambiae larvae, exhibiting a mortality of ca $20 \%$ at $150 \mu \mathrm{g} / \mathrm{ml}$. While an essential oil with larvicidal properties contains caryophyllene oxide as one of many constituents [36], the putative larvicidal effect of caryophyllene oxide itself has, to our knowledge, not been reported. No previous reports on the toxicity of sesamin towards An. gambiae larvae have been found. Dihydronitidine could not be tested in this assay due to low solubility. In view of its lack of activity towards adult mosquitoes and towards brine shrimp larvae (unpublished results), it would seem unlikely that it is a major toxin for An. gambiae larvae. No previous reports on the toxicity of dihydronitidine towards An. gambiae larvae have been found.

\section{Conclusions}

In summary, the toxic effect of hexane extracts of $Z$. heitzii stem bark towards adult insects of the malaria vector Anopheles gambiae [16] appears to be due to the pellitorine content of the extract. An interesting finding is that the activity of pellitorine is enhanced by admixture with other, inactive constituents of the extract. Pellitorine is toxic to An. gambiae larvae, as well. This is the first report of pellitorine toxicity towards Anopheles gambiae adults and larvae.

\section{Competing interests}

The authors declare that they have no competing interests.

\section{Authors' contributions}

$\mathrm{BM}$ and DM participated in the plant collection. NM, KEM, DD and HW participated in the laboratory work. KEM, BM, FC, VC, HJO and HW participated in the design of the studies. KEM and HW drafted the manuscript. All authors read and approved the final manuscript.

\section{Acknowledgements \\ The Research Council of Norway funded this work (FUGE Bio prospecting, project establishment support, project no. 209508/S10). We are grateful to the Norwegian Pharmaceutical Society for a travel grant to Ms. Moussavi. The NMR laboratory of the Chemistry Department, University of Oslo, is acknowledged for the use of the NMR spectrometers.}

\section{Author details}

'School of Pharmacy, Department of Pharmaceutical Chemistry, Section Pharmacognosy, University of Oslo, P.O. Box 1068 Blindern, 0316 Oslo, Norway. ${ }^{2}$ National Polytechnic High School, Marien Ngouabi University, BP 69, Brazzaville, Republic of Congo. ${ }^{3}$ Institut de Recherche pour le Développement (IRD), Maladies Infectieuses et Vecteurs, Ecologie, Génétique, Evolution et Contrôle (IRD 224-CNRS 5290 UM1-UM2), Montpellier, Cedex 5, France.

${ }^{4}$ Department of Mathematical Sciences and Technology, Norwegian University of Life Sciences, P.O. Box 5003, Ås, Norway. ${ }^{5}$ Department of Entomology, Kasetsart University, Bangkok, Thailand.

Received: 11 May 2015 Accepted: 24 September 2015

Published online: 01 October 2015

\section{References}

1. WHO. Malaria fact sheet No94. 2014. http://www.who.int/mediacentre/ factsheets/fs094/en/\#. Accessed 8 May 2015.

2. Silva APB, Santos JMM, Martins AJ. Mutations in the voltage-gated sodium channel gene of anophelines and their association with resistance to pyrethroids - a review. Parasit Vectors. 2014;7:450.

3. Tafokou RBJ. Zanthoxylum heitzii (Aubrév. \& Pellegr.) P.G.Waterman. In: Louppe D, Oteng-Amoako AA, Brink M, editors. PROTA (Plant Resources of Tropical Africa / Ressources végétales de l'Afrique tropicale). 2015. http://uses.plantnetproject.org/en/Zanthoxylum_heitzii_(PROTA). Accessed 8 May 2015.

4. Mikolo B, Matos L, Massamba D, Mamonekene $V$, Miller T. Extracts from the bark of Fagara heitzii (Aubr. et Pel.) (Rutaceae) tree are toxic to two weevils and the American cockroach. Entomol Res. 2009;39:401-5.

5. Betti JL, Lejoly J. Contribution to the knowledge of medicinal plants of the Dja Biosphere Reserve, Cameroon: Plants used for treating jaundice. J Med Plants Res. 2009:3:1056-65.

6. Betti JL. An ethnobotanical study of medicinal plants among the Baka pygmies in the Dja biosphere reserve, Cameroon. Afr Study Monogr. 2004;25:1-27.

7. Betti JL. Medicinal plants sold in Yaoundé markets, Cameroon. Afr Study Monogr. 2002;23:47-64.

8. Nanfack P, Cabral BN, Anatole PC, Joselyne AM, Bruno M, Jeanne NY. The in vitro antisickling and antioxidant effects of aqueous extracts Zanthoxyllum heitzii on sickle cell disorder. BMC Complement Altern Med. 2013:13:162

9. Mengome LE, Akue JP, Souza A, Feuya Tchoua GR, Nsi EE. In vitro activities of plant extracts on human Loa loa isolates and cytotoxicity for eukaryotic cells. Parasitol Res. 2010;107:643-50.

10. Mbaze LM, Lado JA, Wansi JD, Shiao TC, Chiozem DD, Mesaik MA, et al. Oxidative burst inhibitory and cytotoxic amides and lignans from the stem bark of Fagara heitzii (Rutaceae). Phytochemistry. 2009;70:1442-7.

11. Ngouela S, Tsamo E, Connolly JD. Lignans and other constituents of Zanthoxylum heitzii. Phytochemistry. 1994;37:867-9.

12. Bongui JB, Blanckaert A, Elomri A, Seguin E. Constituents of Zanthoxylum heitzii (Rutaceae). Biochem Syst Ecol. 2005;33:845-7.

13. Ahmad S. Flindersine from Fagara heitzii. J Nat Prod. 1984:47:391-2.

14. Dzoyem JP, Guru SK, Pieme CA, Kuete V, Sharma A, Khan IA, et al. Cytotoxic and antimicrobial activity of selected Cameroonian edible plants. BMC Complement Altern Med. 2013;13:78.

15. Mokondjimobe E, Miantezila Basilua J, Barkha S, Dzeufiet $\mathrm{P}$, Chenal $H_{\text {, }}$ Otsudi'andjeka J, et al. Fagaricine, a new immunorestorative phytomedicine from Zanthoxylum heitzii: Preclinical and multicenter cohort clinical studies based on HIV-infected patients in six countries. Phytopharmacology. 2012;2:26-45.

16. Overgaard HJ, Sirisopa P, Mikolo B, Malterud KE, Wangensteen H, Zou YF, et al. Insecticidal activities of bark, leaf and seed extracts of Zanthoxylum heitzii against the malaria vector Anopheles gambiae s.s. Giles. Molecules. 2014;19:21276-90

17. WHO. Guidelines for testing mosquito adulticides for indoor residual spraying and treatment of mosquito nets, WHO/CDS/NTD/WHOPES/GCDPP/ 2006.3. Geneva: World Health Organization; 2006

18. WHO. Guidelines for laboratory and field testing of mosquito larvicides, WHO/ CDS/WHOPES/GCDPP/2005.13. Geneva: World Health Organization; 2005.

19. Lee KH, Choi SU, Lee KR. Sesquiterpenes from Syneilesis palmata and their cytotoxicity against human cancer cell lines in vitro. Arch Pharm Res. 2005;28:280-4

20. Ragasa CY, Ganzon J, Hofilena J, Tamboong B, Rideout JA. A new furanoid diterpene from Caesalpinia pulcherrima. Chem Pharm Bull. 2003:51:1208-10.

21. de Moura N, de Moura H, Ribeiro ECS, Machado E, Ethur N, Zanatta A. Benzophenanthridine alkaloids from Zanthoxylum rhoifolium. Phytochemistry. 1997;46:1443-6.

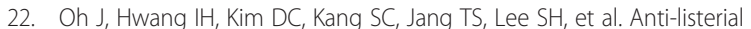
compounds from Asari Radix. Arch Pharm Res. 2010;33:1339-45.

23. Fogang HPD, Womeni HM, Piombo G, Barouh N, Tapondjou LA. Bioefficacy of essential and vegetable oils of Zanthoxylum xanthoxyloides seeds against 
Acanthoscelides obtectus (Say) (Coleoptera: Bruchidae). J Food Prot 2012;75:547-55.

24. Japheth $\mathrm{OO}$, Josphat MC, John VM. Chemical composition and larvicidal activity of Zanthoxylum gilletii essential oil against Anopheles gambiae. Afr J Biotechnol. 2014;13:2175-80.

25. Liu XC, Liu QY, Zhou L, Liu QR, Liu ZL. Chemical composition of Zanthoxylum avicennae essential oil and its larvicidal activity on Aedes albopictus Skuse. Trop J Pharm Res. 2014;13:399-404.

26. Park IK. Insecticidal activity of isobutylamides derived from Piper nigrum against adults of two mosquito species, Culex pipiens pallens and Aedes aegypti. Nat Prod Res. 2012;26:2129-31.

27. Bossou AD, Mangelinckx S, Yedomonhan H, Boko PM, Akogbeto MC, de Kimpe N, et al. Chemical composition and insecticidal activity of plant essential oils from Benin against Anopheles gambiae (Giles). Parasit Vectors. 2013;6:337.

28. Haller HL, McGovran ER, Goodhue LD, Sullivan WN. The synergistic action of sesamin with pyrethrum insecticides. J Org Chem. 1942;7:183-4

29. Noguchi T, Ikeda K, Sasaki Y, Yamamoto J, Seki J, Yamagata K, et al. Effects of vitamin $\mathrm{E}$ and sesamin on hypertension and cerebral thrombogenesis in stroke-prone spontaneously hypertensive rats. Hypertens Res. 2001;24:735-42.

30. Lim Y-P, Ma C-Y, Lin LC-L, Y-H HM-L, Chen J-J, et al. Sesamin: A naturally occurring lignan inhibits CYP3A4 by antagonizing the pregnane $X$ receptor activation. Evid Based Complement Alternat Med. 2012;2012:242810

31. Murray BP. Mechanism-based inhibition of CYP3A4 and other cytochromes P450. Annu Rep Med Chem. 2009;44:535-53.

32. Scott JG. Cytochromes P450 and insecticide resistance. Insect Biochem Mol Biol. 1999;29:757-77.

33. Abbassy MA, Abdelgaleil SAM, Rabie RYA. Insecticidal and synergistic effects of Majorana hortensis essential oil and some of its major constituents. Entomol Exp Appl. 2009;131:225-32.

34. Park IK, Lee SG, Shin SC, Park JD, Ahn YJ. Larvicidal activity of isobutylamides identified in Piper nigrum fruits against three mosquito species. J Agric Food Chem. 2002:50:1866-70.

35. Perumalsamy $\mathrm{H}$, Chang KS, Park C, Ahn YJ. Larvicidal activity of Asarum heterotropoides root constituents against insecticide-susceptible and -resistant Culex pipiens pallens and Aedes aegypti and Ochlerotatus togoi. J Agric Food Chem. 2010:58:10001-6.

36. Baraza LD, Joseph CC, Munissi JJE, Nkunya MHH, Arnold N, Porzel A, et al Antifungal rosane diterpenes and other constituents of Hugonia castaneifolia. Phytochemistry. 2008;69:200-5.

\section{Submit your next manuscript to BioMed Central and take full advantage of:}

- Convenient online submission

- Thorough peer review

- No space constraints or color figure charges

- Immediate publication on acceptance

- Inclusion in PubMed, CAS, Scopus and Google Scholar

- Research which is freely available for redistribution 